\title{
CHOOSING THE BEST URBAN TUNNELS AS SAFE SPACE IN CRISIS USING AHP METHOD: A CASE STUDY IN IRAN
}

\author{
Jalal NAKHAEI ${ }^{\mathrm{a}}$, Mahdi BITARAFAN ${ }^{\mathrm{b}}$, Shahin LALE AREFI ${ }^{\mathrm{c}}$ \\ ${ }^{a}$ Department of Art and Architecture Engineering, Islamic Azad University, Central Tehran Branch, Iran \\ ${ }^{\mathrm{b}}$ Department of Civil Engineering, Research Institute of Shakhes Pajouh, P.O. Box 81655-1537, Isfahan, Iran \\ ${ }^{c}$ Department of Civil Engineering, University of Mohaghegh Ardabili, P.O. Box 56199-11397, Ardabil, Iran \\ E-mails: ajalal.nakhei@gmail.com; ${ }^{\mathrm{b}}$ mb_civil90@yahoo.com; \\ cshahin.arefi@gmail.com (corresponding author)
}

Received 11 April 2015; accepted 21 May 2015

\begin{abstract}
In recent decades, experiences resulted from Modern wars have shown that aggressive armies have targeted vital and sensitive resources of the other countries in order to decrease their expenses in one hand and increase damages in other hand, defending countries transmit their critical and sensitive facilities to safe underground spaces in order to reduce damages, and experience has shown that underground spaces receive the least damage. This study tries to examine and prioritize Tehran tunnels as undergroundsafe spaces at crisis times regarding their structural parameters and also civil defense arrangements. It could accelerate the selection and creation of underground-safe spaces at crisis and it also can decrease construction and maintenance costs. This study has used AHP method to evaluate Tehran tunnels. In this regard five indices have been chosen by asking experts in the related fields and to evaluate and select a proper way to choose the best one as an urban-safe space. Finally, the investigated tunnels are prioritized as Tohid weighted as 0.349 , Niyayesh weighted as 0.279 , Resalat weighted as 0.197 and finally Amir Kabir weighted as 0.164 respectively that showed Tohid tunnel is the best urban-safe space and, Niyayesh, Resalat and Amir Kabir tunnels take the next places in the ranking, respectively.
\end{abstract}

Keywords: urban tunnels, safe space, AHP, crisis, tunnels.

\section{Introduction}

The history of wars shows that beside the human progression in creating new weapons in wars through time, defensive measures have also been progressed and usually these two develop together at the same time. Underground shelters have been one of the most important defensive measures against war threats and hostile forces, from past to present; human beings have benefited from such underground tunnels in any way at different times. Not only are these underground structures very important and beneficial for human beings, but also they have been very considerable for other creatures, for example, some animals build their dens underground to be secure from the threat of hunters.

In recent decades by studying modern wars of twenty first century, it has been shown that hostile forces, using some destructive strategies, have focused on the destructing vital and sensitive centers and their bombardment in order to destroy the nation's volition and economic, military and politic power of attacked country. Therefore, it is very essential to protect vital undergrounds and the very expensive buildings in the country. In recent years, from the civil defense point of view, underground structures have been regarded as the safe structures against air and missile attacks. So, to decrease underground structures vulnerability and to protect operational and strategic structures from enemies' weapons, they are moved to a proper depth in the underground. Numerous evidences suggest that during massive wars, surface structures have been destructed much more than underground structures. So, it could be concluded that urban underground spaces such as urban tunnels are very important and they could be used as underground shelters and safe spaces. 
In recent decades, experts and officials of Tehran municipality, regarding the volume of traffic in Tehran, have constructed urban tunnels to connect transportation networks of Tehran city to each other. So, as mentioned before, proper sites have been created in Tehran city through constructing urban tunnels. Such tunnels could be used as underground shelters and safe spaces in crisis times because they are underground tunnels.

This study tries to investigate and evaluate some of Tehran's tunnels which are considered as proper shelters in crisis times from urbanism, civil engineering and civil defense point of view. It also tries to prioritize Tehran's tunnels using indexes coming from librarian studies and interviewing pundits through questionnaire.

Many researches and laws were compiled about designing and constructing underground tunnels; this implies that in contemporary times, such underground safe spaces are very important to consider. For example, in Persian resources, Fesharaki and Gharbaghi (2011) have investigated designing and constructing safe shelters specifically multi-purposeful shelters regarding structural and interior design issues. In other study Amiri (2011) has focused on the interior spaces of general shelters and he has submitted a pattern to design interior spaces of shelters and their connections. He also in another study in 2011 has referred to psychological issues in designing the interior general shelters. Zahedifar in 2010 has studied the principles of designing in order to immunize and equip vital underground spaces. Technical principles to construct shelters have been also submitted by the department of housing and urban development, shelter and safe structures office in 1990. Kashi (2009) has investigated the civil defense regarding habitation of people in tunnels in his M.A thesis. Vafamehr (2011) has studied civil defense in designing and implementing safe shelter structures. In another study, Khandan (2010) has worked on Ergonomic studies relating to designing safe spaces in civil defense. At international level, there are also some studies such as:

- Cano-Hurtado and Canto-Perello (1999), work regarding sustainable development of urban underground space for utilities.

- Durmisevic (1999) studied the future of the underground space.

- Kenward et al. (2002) studied design recommendations for multi-storey and underground car parks.

- FEMA 453 (2006) describes application of shelters and safe rooms design.

- US Department of Homeland Security in 2006 analysed protection of shelters from storms
- Bobylev (2010) studied an underground space in the Alexanderplatz Area, Berlin.

- He et al. in 2012 applied quantitative research on the capacity of urban underground space - The case of Shanghai, China.

- Sterling et al. (2012) analyzed sustainability issues for underground space in urban areas.

- Lale Arefi, Bitarafan (2013) studied assessment of various methods of rehabilitation in underground structures against threats using AHP method.

- Bitarafan et al. (2013) have selected the optimal composition of architectural forms from the perspective of civil defense using AHP and IHWP methods.

- Hashemkhani Zolfani et al. (2013) were creating a new hybrid MCDM method for selection of the optimal alternative of mechanical longitudinal ventilation of tunnel pollutants during automobile accidents.

- Hoeven, Nes (2014) were improving the design of urban underground space in metro stations using the space syntax methodology.

Which have evaluated the terms and conditions of designing and constructing different kinds of shelters and underground tunnels. The importance of constructing shelters and safe spaces, specifically underground tunnels, is so obvious; therefore, Tehran's underground tunnels could be used as safe spaces and shelters in crisis times. It is a case study intended to investigate some of Tehran's tunnels.

The advantages of this study, it can be pointed to the information of related organizations and residents of Tehran about functions of four important urban tunnels of the city for utilization in the crisis term in addition to determination of capability amount of each tunnel in order to be converted into a safe space.

To choose indexes of prioritizing Tehran tunnels, this study uses above mentioned researches and existing bylaws and also it depends on experts' ideas. Finally, using data resulting from experts> opinions and selected indexes Tehran tunnels were prioritized.

\section{Urban tunnels}

In this study, the tunnels have been selected based on the pundits and experts view point regarding the effective parameters in each tunnel. The selected tunnels include:

\section{Resalat tunnel (A1)}

It is a $950 \mathrm{~m}$ tunnel which ties the east to the west in the north and central north area. It is considered as part of East-West Highway. Resalat Highway is one of the main routes of Tehran (Fig. 1). It is one of the lon- 


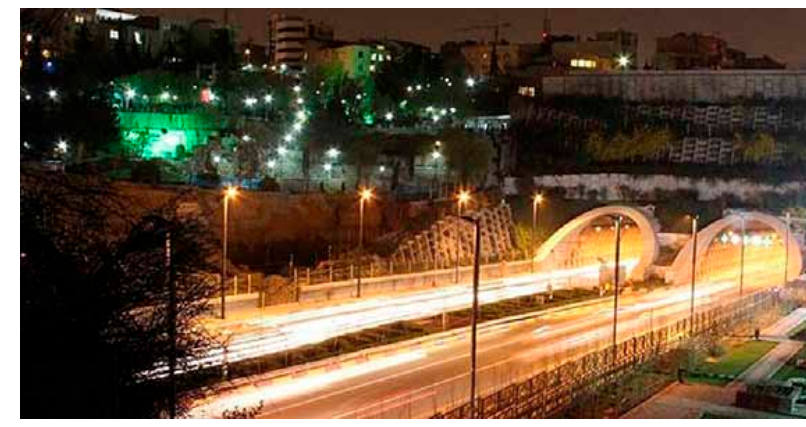

Fig. 1. Resalat tunnel (Hamshahrionline 2015)

gest East-West routes that connect the east of Tehran from Damavand Street to the most western areas which is Rahahan Town. Certainly, the completion of Resalat highway across the city has a great influence on the reduction of traffic in "Shahid Hemat" and "Shahid Hakim" highways. It contains two tunnels for opposite directions. Each tunnel contains three lanes. The length of this highway is $1740 \mathrm{~m}$ (between Modares and Kordestan highways) that $840 \mathrm{~m}$ of its total length is related to the big tunnel and $150 \mathrm{~m}$ of it is the small one. Their interior entrance and excavation diameter are $13.5 \mathrm{~m}$ and $16.9 \mathrm{~m}$ respectively. The longitudinal slop in long tunnels is $2.7 \%$ and in short ones is $4 \%$.

It contains a two-sided road, and each side has a $950 \mathrm{~m}$ tunnel; so, this highway contains $1900 \mathrm{~m}$ tunnel in total. Each of these tunnels contains a long tunnel, which is from Africa square till the east of Nezami Ganjavi, and a short tunnel, which is from the west of Nezami Ganjavi till the end of Seyyed Jammal Aldin Asadi.

\section{Amir Kabir tunnel (A2)}

Amir Kabir tunnels project was implemented in the past from Amin Hozour crossroads till 17 Shahrivar Street (Fig. 2). But now, in a new project some part of it has been modified (part T1); it is continued as a TU tunnel $69 \mathrm{~m}$ in length crossing from 17 Shahrivar. Underground T2 which is $220 \mathrm{~m}$ in length has been located between 17 Shahrivar and Shokoufeh Street. The path is continued from Shokoofeh Street till Kalantari square as part T3 which is $170 \mathrm{~m}$ in length. The rest of the path is a tunnel from Doroodiayan Street till its intersection with Nicknam Blvd which length is $525 \mathrm{~m}$. This intersection is divided into two routes by a tee underground structure. The north route along with Doroodiyan Street, which is a $101 \mathrm{~m}$ tunnel in length, is connected to the north-south of Imam Ali autobahn, the south route, which is a $270 \mathrm{~m}$ tunnel in length, is connected from Nicknam Blvd to southnorth of Imam Ali autobahn.

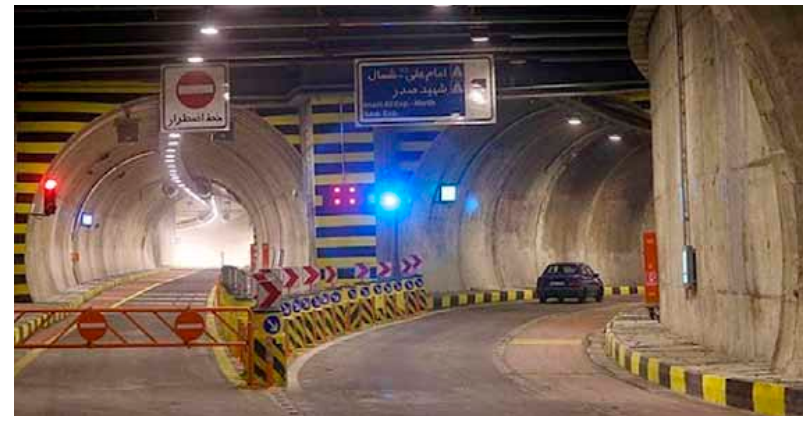

Fig 2. Amir Kabir tunnel (Fars News Agency 2015)

Technical characteristics:

1. Part T1 is relatively $200 \mathrm{~m}$ in length with a box section. It is a two-sided road and each side has two lanes.

2. Part TU is relatively $70 \mathrm{~m}$ in length with a tunnel section. Its section area is $186 \mathrm{sq} . \mathrm{m}$.

3. Part T2 is relatively $220 \mathrm{~m}$ in length with a box section. It is a two-sided road and each side has two lanes. It also must be mentioned that above the box there is a way of a three-storey parking at the street level and a commercial complex.

4. Part T3 with a tunnel section that is $170 \mathrm{~m}$ in length and 283 sq. $m$ sectional area.

5. Part T4 has several tunnel sections: a tunnel with 137 sq. m sectional area and 2.5 transmission lines which are $525 \mathrm{~m}$ and $150 \mathrm{~m}$ in length, another tunnel with 97 sq. $m$ sectional area and 2.5 transmission lines which are $101 \mathrm{~m}$ and 110 $\mathrm{m}$ in length.

\section{Tohid tunnel (A3)}

Tohid tunnel consists of tunnels posited alongside each other which are $2136 \mathrm{~m}$ in length (Fig. 3). Each of these tunnels has three two-ways bands. It is the first tunnel which connects north of Tehran to its south; it also connects Chamran to Navabsafavi highway. The construction of this tunnel was a record as it was done in just

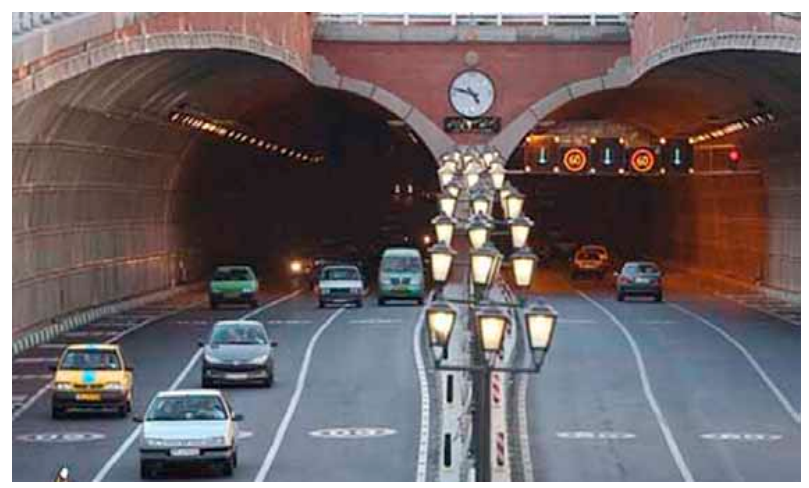

Fig. 3. Tohid tunnel (Fars News Agency 2015) 
30 months. It is the biggest urban tunnel in Tehran; the construction started at 29/ Khordad/ 1386 and done at 12/ Bahman/1388.

Technical characteristics:

1. Type: twin,

2. Length: $2136 \mathrm{~m}$,

3. The average slope length: 4 percent,

4. Lanes of each band: 3 ,

5. External width: $30 \mathrm{~m}$,

6. The maximum depth: $31.5 \mathrm{~m}$.

\section{Niyayesh tunnel (A4)}

Niyayesh tunnel involves north, south, Kordestan and 04 tunnels (Fig. 4). These tunnels with access and communication tunnels are $8560 \mathrm{~m}$ in length; if ramps are included, the total length of Niyayesh tunnel project will be equal to $10252 \mathrm{~m}$. The West-East traffic is transmitted to Valiyeasr, Isfandyar and Modares highways as Niyayesh highway is finished at Vliyeasr intersection and also East-West traffic of Sadr highway is transferred to Modares and Chamran highways and then leads to a heavy traffic in the area. Two tunnels have been designed from East to West and West to East to solve the traffic problem of this area. So, the traffic of Sadr highway enters directly to Niyayesh Highway through an East-West tunnel and also the heavy traffic of West to East Niyayesh Highway enters directly Sadr highway through a tunnel. Technical characteristics of Niyayesh tunnel shown in Table 1.

Table 1. Technical characteristics of Niyayesh tunnel

\begin{tabular}{cccc}
\hline Tunnel & $\begin{array}{c}\text { The length } \\
\text { of ramp }(\mathbf{m})\end{array}$ & $\begin{array}{c}\text { The length } \\
\text { of tunnel }(\mathbf{m})\end{array}$ & $\begin{array}{c}\text { The total } \\
\text { length }(\mathbf{m})\end{array}$ \\
\hline North tunnel & 360 & 2895 & 3255 \\
\hline South tunnel & 341 & 2599 & 2940 \\
\hline Kordestan tunnel & 300 & 950 & 1250 \\
\hline 04 tunnel & 408 & 194 & 602 \\
\hline Sum & 1409 & 6638 & 8047 \\
\hline
\end{tabular}

Access and communication tunnels: The length of ramp $337 \mathrm{~m}$; the length of tunnel 2381; the total length 2718

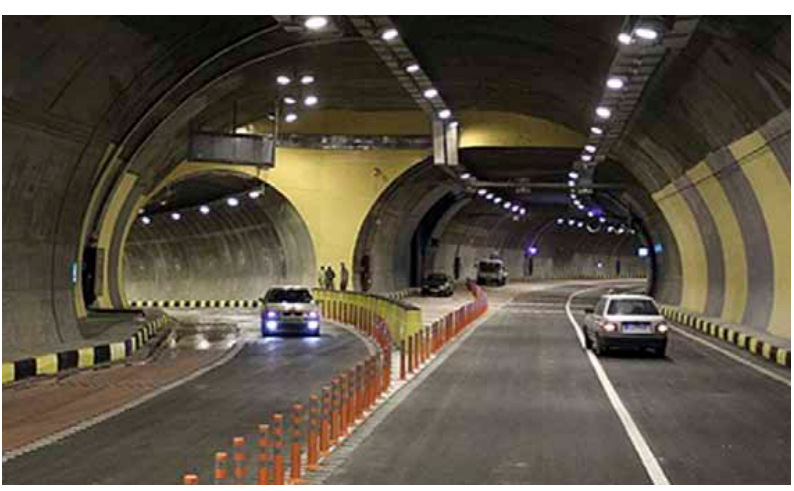

Fig. 4. Niyayesh tunnel (Fars News Agency 2015)
Tunnel entrances:

1. The west to east direction of Niyayesh highway (in opposite of Shahrake Fajr).

2. The south to north direction of Kordestan highway (the north end of Kordestan highway).

3. The end of east to west of Sadr highway, before Modares highway (entering from the multi-story bridge).

Tunnel exit:

1. The east to west direction of Niyayesh highway (after Kordestan bridge).

2. The north to south direction of Kordestan highway (the north end of Kordestan highway).

3. The trailhead of west to east of Sadr highway (existing the multi-storey bridge).

The emergency exit directions (to sidewalks and roadways):

1. The exit direction to Valiyeasr Street which is in the vicinity of the main door of Melat Park.

2. The exit direction to Golshahr Blvd.

3. The exit direction to Nahid street which is in the vicinity of the existence of Modares highway to Sadr highway.

4. The exit direction of Kordestan tunnel to Kordestan highway.

The emergency directions between tunnels (the sidewalks and roadways):

1. Four emergency directions between north and south tunnels (between Valiyeasr street and Modares highway) posited in every $250 \mathrm{~m}$.

2. The exit direction from south tunnel to Kordestan tunnel to Golshahr Blvd.

The connecting directions of roadways between south and north tunnels due to the emergency times:

1. The connecting direction of Nonahalan.

2. The connection direction of Melat Park.

3. The connecting direction of Kordestan under bridge.

\section{Determining effective parameters influencing on the prioritizing}

The effective parameters on prioritizing of Tehran tunnels have been identified through interviewing and polling. The effective parameters include:

\section{Resistance to explosion (X1)}

Explosive ordnances have been always at the center of human attention due to their tremendous destructive power and high energy. Such explosive ordnances are frequently used in construction and mining activities such as mining extraction; tunnels and roads construction, removing natural barriers and it is also used in military activities to create types of military we- 
apons. On the other hand, the structures' resistance against bombing and missile attacks is considerably important. The ultimate goal of this parameter is to prevent wave penetration and its quivers into the shelters. If explosion waves penetrate in shelters, people and installations which are in such areas will damage irreversibly; in other words, the more resistance are the materials used in external walls, the less penetration of waves and consequently the less damages to the shelters and people will be.

\section{Useable as a safe area and emergency settings (X2)}

In crisis times, there is not enough time to construct new shelters; so urban multi-functional areas are used as safe areas and emergency settings. So, it is a very important parameter in prioritizing urban tunnels. In order to examining the urban tunnels in terms of safe area and emergency setting parameter following subparameters include the speed of preparation, the available facilities and the cost of changing the use, must be considered for each tunnel.

\section{The speed of preparation (X2-1)}

In crisis times, the speed of preparing safe areas such as tunnels to be an accommodation for people is very important. So, having a futuristic view, we should provide the essentialities of shelters in urban transporting tunnels in order to decrease the time of shelter preparations.

\section{The available facilities (X2-2)}

Controlling and monitoring systems in urban tunnels, which have been installed due to monitoring and surveillance, could be used in crisis times in order to monitor and manage the shelters. So, it could be concluded that the more advanced and smarter are these systems, the more useful would be for managing and controlling the shelters in crisis times.

The cost of changing the use (X2-3)

During changing the use of urban areas, especially urban transporting tunnels, to the shelters in crisis times, the cost must be come into consideration. The less the cost of changing the use, the more preferred it would be and the intended area would be prepared and designed with a more speed.

\section{The capability of emergency evacuation (X3)}

Sometimes in crisis times, it is a necessity to evacuate people from shelters quickly due to some accidents in shelters and safe areas; so, it is very essential that the shelters equip with evacuation emergency facilities. A tunnel equipping with the emergency is dependent on other factors that we will refer to them in the following.

\section{Tunnel's dimensions (X3-1)}

Special measures are needed in urban master plans to cope with natural disasters or humanitarian crisis. One of such measures is to use dual functioning urban tunnels in crisis times. The used tunnels need to have specific dimensions regarding the number of people. On other hand, the smaller the tunnels' cross-sectional is, the more resistance against explosion will be and vice versa. So, considering the usage of the tunnel, we should focus on the tunnel dimension.

The connectivity between the two ways of a tunnel (X3-2)

In the construction of urban two-ways tunnels, there are some considerations that must come into account. The tunnels must be constructed in a way that if any disaster happens such as fire, it must not exceed other parts or adjacent tunnels. On other hand, the tunnels must be enough accessible to use alternative access in crisis times for evacuation and displacement purposes.

\section{The emergency exists (X3-3)}

The dimensions of an emergency exits must be designed in a way that 3 people be able to exist the place at the same time. According to architectural standards, $175 \mathrm{~cm}$ area is needed in order to 3 people be able to stand next to each other easily. 10 more percent is needed for walking and $15 \%$ must be added to this area for running. There is a logical relationship between the number of doors and the people inside the structure. The number and the dimensions of the emergency exists must be determined according to standards regarding the emergency situation and the necessity of existence.

\section{The ventilation system (X4)}

As the shelters contain a large number of populations in crisis times, some ventilation systems are needed. The lack of ventilation systems in such areas could lead to disaster and to jeopardize the public health.

\section{The possibility of blocking the path and}

the existence of an alternative path (X5)

During changing the urban tunnels to emergency settings and shelters, transportation paths connecting by the tunnels would be blocked. Authorities must take some measures to provide alternative accessible paths. The lack of the alternative paths when the tunnels are blocked could lead to serious disasters and it also involves high costs.

The hierarchical tree is a graphical showed in the Figure 5 (goal, criteria, and selecting options). 


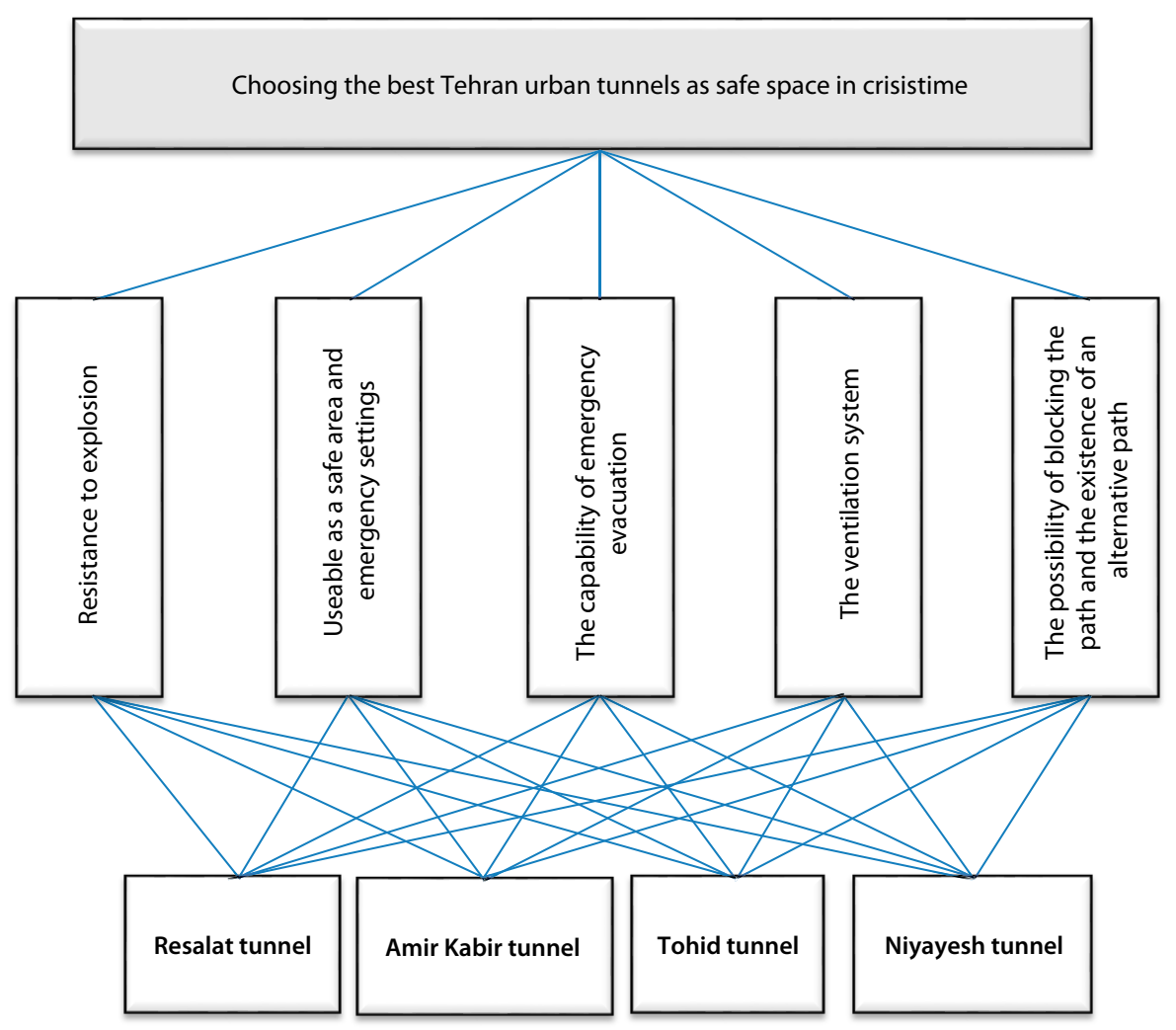

Fig. 5. Graphical hierarchy tree of choosing the best Tehran urban tunnels as safe space in crisis time

\section{Methodology}

This study has identified proper urban tunnels through interviewing experts in Civil engineering, architecture, urbanism and civil defense to evaluate Tehran' tunnels for the times of threats. Essential indexes relating to designing shelters and safe spaces have been investigated, the main axes (Table 2) have been identified, some questionnaires have been answered by 30 experts in order to ranking effective indexes and then the indexes have been ranked by importance as a Likret scale (1-9) using group decision making method on the base of scale test model. Cronbach $\alpha$ has been also used to examine the questionnaires' reliability. The reliability of questionnaire was 93.75 percent. So, as its reliability is more than 75 percent, it is an acceptable one. The compatibility of test matrices has been examined and all matrices in this study have less than 0.1 compatibility and those above 0.1 were removed.

The Analytical Hierarchical Process (AHP) proposed by Saaty (1980) for the first time. This method is composed of three main functions including structuring the complexity, assessing base on the relative scale and composition. The main function of this method is to compute the relative importance of a set of alternatives in a multi-criteria decision. Using this method helps to convert qualitative indexes to quantitative ones (Badri 2001). AHP method is made of three main parts:
Table 2. Statistics of experts

\begin{tabular}{ccc}
\hline Specialty & Education level & Number of people \\
\hline Civil \\
\cline { 2 - 3 } engineering & PhD & 4 \\
\hline \multirow{2}{*}{ Architecture } & M.S & 3 \\
\cline { 2 - 3 } & PhD & 4 \\
\hline \multirow{2}{*}{ Urbanism } & M.S & 3 \\
\cline { 2 - 3 } & PhD & 6 \\
\hline \multirow{2}{*}{ Civil defense } & M.S & 2 \\
\cline { 2 - 3 } & PhD & 5 \\
\hline
\end{tabular}

structure of model, comparative judgments of options and criteria and finally, combination of preferences (Fouladgar 2011).

Recent studies in which this method was discussed are:

- Fouladgar et al. (2011) applied an integrated model for prioritizing strategies of the Iranian mining sector.

- Sivilevicius (2011a) applied modeling the interaction of transport system elements.

- Sivilevicius (2011b) studied application of expert evaluation method to determine the importance of operating asphalt mixing plant quality criteria and rank correlation. 
- Bitarafan et al. (2012) studied AHP technique in reconstructing damaged areas in natural crises.

- Bitarafan et al. (2013d) selected the best design scenario of the smart structure of bridges for probably future earthquakes.

- Nosal, Solecka (2014) used AHP method for multi-criteria evaluation of variants of the integration of urban public transport.

- Hruška et al. (2014) used AHP method for selection of supplier.

- Gudienè et al. (2014) used AHP approach to identification and evaluation of the critical success factors for construction projects in Lithuania.

The first step in analytical hierarchical process method includes decomposing the problem to a hierarchical structure including purposes, criterions, sub-criterions and options in which the purpose is at the top, criteria are in the middle and sub-criteria posited at the lowest point in the hierarchical structure. In the second stage, regarding the made hierarchy, decision-makers do paired comparison among elements. Saaty proposes a 1-9 scale (Table 3) to judge between two elements.

Table 3. A nine scale of the amount of importance and the related explanations (Saaty 1980)

\begin{tabular}{cc}
\hline Definition & The amount of importance \\
\hline Extremely & 1 \\
\hline Very Strongly & 3 \\
\hline Strongly Preferred & 5 \\
\hline Moderately Preferred & 7 \\
\hline Equally preferred & 9 \\
\hline Between above distances & $2,4,6,8$ \\
\hline
\end{tabular}

In this stage, the decision makers compare two elements in relation to their higher position element and then they present a score based on the Table 3 to show the superiority of first one to the second one.

Third stage is the stage of forming adaptive matrixes which is based on the gathered data in previous stage in terms of an introduction to the calculation of rates.

It must be noted that to calculate the relative rates, first of all the elements compared with each other by pairing them and then the paired comparison matrix (for every element of each stage) is formed. Next, the relative rate is calculated using this matrix. Generally, a paired comparison matrix is shown as Equation 1 in which $a_{i j}$ is the ratio of $i$ to $j$. having the amount of $a_{i j}$, we could calculate the rate of elements, $W_{i}$, through:

$$
A=\left(a_{i j}\right) i, j=1,2,3, \ldots, n .
$$

Here, the inconsistency rate of paired comparison matrix is an important issue. Each paired comparison matrix may be consistent or inconsistent. If this matrix is consistent, $W_{i}$ is calculated simply by normalizing the elements of each column. But if the matrix is inconsistent, calculating simple rate is not an easy job and there are four main ways of calculating this: least squares method, logarithmic least squares method, special vector method and approximative method. It must be noted that according to "Saaty" the least acceptable rate of inconsistency is equal to 0.1 . It is very considerable to note that a "decision maker who is aware of options and parameters" is needed in order to compare options paired together and to set the preferences.

Let $C=\left\{C_{j} \mid j=1,2, \ldots, n\right\}$ be the set of criteria. The result of the pairwise comparison on $n$ criteria can be summarized in an $(n \times n)$ evaluation matrix $A$ in which every element $a_{i j}(i, j=1,2, \ldots, n)$ is the quotient of weights of the criteria, as shown in Eq. 2:

$$
A=\left[\begin{array}{cccc}
a_{11} & a_{12} & \ldots & a_{1 n} \\
a_{21} & a_{22} & \ldots & a_{2 n} \\
\vdots & \vdots & \ddots & \vdots \\
a_{n 1} & a_{n 2} & \ldots & a_{n n}
\end{array}\right], a_{i i}=1, a_{j i}=1 / a_{i j}, a_{i j} \neq 0 .
$$

At the third step, the mathematical process commences to normalize and find the relative weights for each matrix. The relative weights are given by the right eigenvector $(w)$ corresponding to the largest eigenvalue $\left(\lambda_{\max }\right)$, as follows:

$$
A w=\lambda_{\max } w .
$$

If the pairwise comparisons are completely consistent, the matrix $A$ has rank 1 and $\lambda_{\max }=n$.

In this case, the weights can be obtained by normalizing any of the rows or columns of A (Wang, Yang 2007). The quality of the output of the AHP is strictly related to the consistency of the pairwise comparison judgments (Bambach 2010). The consistency is defined by the relation between the entries of $A: a_{i j} \times a_{j k}=a_{i k}$. The consistency index (CI) is:

$$
\mathrm{CI}=\left(\lambda_{\max }-n\right) /(n-1) .
$$

The final consistency ratio (CR), using which one can conclude whether the evaluations are sufficiently consistent, is calculated as the ratio of the CI to the random index (RI), as indicated in Eq. 5:

$$
\mathrm{CR}=\mathrm{CI} / \mathrm{RI} \text {. }
$$

The CR index should be lower than 0.10 to accept the AHP results as consistent (Ișıklar, Büyüközkan 2007). If the final consistency ratio exceeds this value, the evaluation procedure has to be repeated to improve the consistency (Da gdeviren 2008). The CR index 
could be used to calculate the consistency of decision makers as well as the consistency of all the hierarchy (Wang, Yang 2007).

\section{AHP results}

Using the above mentioned questionnaire and its results, the paired comparison judging matrix (Table 3) formed. In the following the paired comparison judging matrix of each area was determined regarding each parameter as follow.

Using the above mentioned questionnaire and its results, the paired comparison judging matrix (Table 3) formed. In the following the paired comparison judging matrix of each area was determined regarding each parameter as follow.

In this part, the paired judging matrixes of selected parameters, which are resulted from gathered data through questionnaire, will be presented. The obtained data from questionnaires have been rated through which the parameters have been prioritized as follow respectively: first, the resistance for explosion weighted as 0.402; second, usable as a safe area and emergency setting rated as 0.218 ; third, the possibility of blocking the path and the existence of an alternative path for the tunnel rated as 0.161 ; ventilation system rated as 0.120 , and finally the capability of emergency evacuation rated as 0.098 . In the following matrix, the standard deviation is calculated as 0.01 . It must be mentioned that each of the two parameters, namely the capability of emergency evacuation and useable as a safe area and emergency settings, has three subparameters shown in Tables 4 and 5.

Here, the paired judging matrix of selected subparameters of usable as safe area and emergency setting

Table 4. The paired comparison judging matrix of selected parameters

\begin{tabular}{ccccccc}
\hline & X1 & X2 & X3 & X4 & X5 & Weights \\
\hline X1 & 1 & 1.65 & 4.04 & 3.47 & 2.81 & $\mathbf{0 . 4 0 2}$ \\
\hline X2 & & 1 & 2.39 & 1.82 & 1.16 & $\mathbf{0 . 2 1 8}$ \\
\hline X3 & & & 1 & 0.637 & 0.813 & $\mathbf{0 . 0 9 8}$ \\
\hline X4 & & & & 1 & 0.602 & $\mathbf{0 . 1 2 0}$ \\
\hline X5 & & & & & 1 & $\mathbf{0 . 1 6 1}$ \\
\hline
\end{tabular}

Note: $\mathrm{IR}=0.01$

Table 5. The paired comparison judging matrix of selected subparameters of usable as safe area and emergency

\begin{tabular}{ccccc}
\hline & $\mathrm{X} 2-1$ & $\mathrm{X} 2-2$ & $\mathrm{X} 2-3$ & Weight \\
\hline $\mathrm{X} 2-1$ & 1 & 0.274 & 0.413 & $\mathbf{0 . 1 4 3}$ \\
\hline $\mathrm{X} 2-2$ & & 1 & 1.23 & $\mathbf{0 . 4 8 7}$ \\
\hline $\mathrm{X} 2-3$ & & & 1 & $\mathbf{0 . 3 7 0}$ \\
\hline
\end{tabular}

Note: $\mathrm{IR}=0.01$ is presented regarding gathered data from questionnaires. The subparameters are prioritized by AHP method as follow: among all the subparameters which are examined, the subparameter of available facilities in tunnels rated as 0.487 is the first priority and the cost of changing the use subparameter weighted as 0.370 is the second one, and finally, the speed of preparation is the last (third) priority which is rated as 0.143 .

In this part, the paired judging matrix of selected subparameters of the capability of emergency evacuation is presented regarding gathered data from questionnaires. The subparameters are prioritized by AHP method as follow: among all the subparameters which are examined, the subparameter of tunnel's dimension weighted as 0.576 , the emergency exists weighted as 0.264 are the first and second priorities respectively and finally the connectivity between the two ways of a tunnel is the third one (Table 6).

Table 6. The paired comparison judging matrix of selected subparameters of the capability of emergency evacuation

\begin{tabular}{ccccc}
\hline & X3-1 & X3-2 & X3-3 & Weight \\
\hline X3-1 & 1 & 3.25 & 2.42 & 0.576 \\
\hline X3-2 & & 1 & 0.546 & 0.160 \\
\hline X3-3 & & & 1 & 0.264 \\
\hline
\end{tabular}

Note: $\mathrm{IR}=0.01$

In this part, the paired judging matrix of each tunnel is examined in terms of the resistance for explosion parameter. As the results show in the Table 6, the tunnels are prioritized from first to fifth as Vahid tunnel weighted as 0.483 , Niyayesh tunnel weighted as 0.226 , Amir Kabir weighted as 0.215 and finally Resalat weighted as 0.076 respectively. The standard deviation in the following matrix is 0.01 (Table 7).

Table 7. The paired comparison judging matrix of each tunnel in terms of the resistance for explosion parameter

\begin{tabular}{cccccc}
\hline X1 & A1 & A2 & A3 & A4 & Weight \\
\hline A1 & 1 & 0.312 & 0.183 & 0.331 & 0.076 \\
\hline A2 & & 1 & 0.442 & 0.840 & 0.215 \\
\hline A3 & & & 1 & 2.45 & 0.483 \\
\hline A4 & & & & 1 & 0.226 \\
\hline
\end{tabular}

Note: $\mathrm{IR}=0.01$

Here, the paired judging matrix of each tunnel is analyzed in terms of usable as a safe area and emergency setting parameter in its subparameter, the speed of preparation. As the results show in the Table 8 , the tunnels are prioritized from first to fifth and Vahid tunnel weighted 0.538 , Niyayesh tunnel weighted 0.273 , Resalat weighted 0.126 , and finally Amir Kabir weighted 0.063 respectively. The standard deviation in the following matrix is 0.01 . 
Table 8. The paired comparison judging matrix of each tunnel in terms of usable as a safe area and emergency setting parameter the speed of preparation

\begin{tabular}{cccccc}
\hline X2-1 & A1 & A2 & A3 & A4 & Weight \\
\hline A1 & 1 & 2.31 & 0.218 & 0.429 & $\mathbf{0 . 1 2 6}$ \\
\hline A2 & & 1 & 0.145 & 0.216 & $\mathbf{0 . 0 6 3}$ \\
\hline A3 & & & 1 & 2.25 & $\mathbf{0 . 5 3 8}$ \\
\hline A4 & & & & 1 & $\mathbf{0 . 2 7 3}$ \\
\hline
\end{tabular}

Note: $\mathrm{IR}=0.01$

In this part, the paired judging matrix of each tunnel is analyzed in terms of usable as a safe area and emergency setting parameter in its subparameter, the available facilities. As the results show in the Table 9, the tunnels are prioritized from first to fifth and Niyayesh tunnel weighted 0.535 , Resalat weighted 0.235, Amir Kabir weighted 0.117, and finally Tohid weighted 0.114 respectively. The standard deviation in the following matrix is 0.01 .

Table 9. The paired judging matrix of each tunnel in terms of usable as a safe area and emergency setting parameter the available facilities in tunnel

\begin{tabular}{cccccc}
\hline X2-2 & A1 & A2 & A3 & A4 & Weight \\
\hline A1 & 1 & 2.08 & 2.12 & $1 / 2.41$ & 0.235 \\
\hline A2 & & 1 & 1.04 & $1 / 4.49$ & 0.117 \\
\hline A3 & & & 1 & $1 / 4.53$ & 0.114 \\
\hline A4 & & & & 1 & 0.535 \\
\hline
\end{tabular}

Note: $\mathrm{IR}=0.01$

Here, the paired judging matrix of each tunnel is analyzed in terms of the usable as a safe area and emergency setting parameter in its subparameter, the cost of changing. As the results show in the Table 10, the tunnels are prioritized from first to fifth and Niyayesh tunnel weighted 0.445 , Tohid weighted 0.329 , Resalat tunnel weighted 0.137, and finally Amir Kabir weighted 0.089 respectively. The standard deviation in the following matrix is 0.01 .

In this part, the paired judging matrix of each tunnel is analyzed in terms of the capability of emergency evacuation in its subparameter which is tunnel/s dimension. As the results show in the Table 11, the

Table 10. The paired judging matrix of each tunnel in terms of the usable as a safe area and emergency setting parameter the cost of changing

\begin{tabular}{cccccc}
\hline X2-3 & A1 & A2 & A3 & A4 & Weight \\
\hline A1 & 1 & 1.53 & 0.450 & $1 / 3.48$ & 0.137 \\
\hline A2 & & 1 & 0.267 & 0.199 & $\mathbf{0 . 0 8 9}$ \\
\hline A3 & & & 1 & 0.793 & 0.329 \\
\hline A4 & & & & 1 & $\mathbf{0 . 4 4 5}$
\end{tabular}

Note: $\mathrm{IR}=0.01$
Table 11. The paired judging matrix of each tunnel in terms of the capability of emergency evacuation_ tunnels' dimension

\begin{tabular}{cccccc}
\hline X3-1 & A1 & A2 & A3 & A4 & Weight \\
\hline A1 & 1 & 3.47 & 2.63 & 0.246 & 0.205 \\
\hline A2 & & 1 & 0.543 & 0.133 & 0.064 \\
\hline A3 & & & 1 & 0.149 & 0.095 \\
\hline A4 & & & & 1 & 0.636 \\
\hline
\end{tabular}

Note: $\mathrm{IR}=0.02$

tunnels are prioritized from first to fifth and Niyayesh tunnel weighted 0.636 , Resalat weighted 0.205 , Tohid weighted 0.095 , and finally Amir Kabir weighted 0.064 respectively. The standard deviation in the following matrix is 0.02 .

Here, the paired judging matrix of each tunnel is analyzed in terms of the capability of emergency evacuation in its subparameter which is the connectivity between the two ways of a tunnel. As the results show in the Table 12, the tunnels are prioritized from first to fifth and Niyayesh tunnel weighted 0.591, Resalat weighted 0.203 , Tohid weighted 0.132 , and finally Amir Kabir weighted 0.075 respectively. The standard deviation in the following matrix is 0.01 .

In this part, the paired judging matrix of each tunnel is analyzed in terms of the capability of emergency evacuation in its subparameter which is emergency exists. As the results show in the Table 13, the tunnels are prioritized from first to fifth and Niyayesh tunnel weighted 0.444, Amir Kabir weighted 0.340, Resalat weighted 0.175 , and finally Tohid weighted 0.059 respectively. The standard deviation in the following matrix is 0.01 .

Table 12. The paired judging matrix of each tunnel in terms of the capability of emergency evacuation - the connectivity between the two ways of a tunnel

\begin{tabular}{cccccc}
\hline X3-2 & A1 & A2 & A3 & A4 & Weight \\
\hline A1 & 1 & 3.22 & 1.45 & 0.303 & 0.203 \\
\hline A2 & & 1 & 0.565 & 0.153 & 0.075 \\
\hline A3 & & & 1 & 0.211 & 0.132 \\
\hline A4 & & & & 1 & 0.591
\end{tabular}

Note: IR $=0.01$

Table 13. The paired judging matrix of each tunnel in terms of the capability of emergency evacuation - emergency exits

\begin{tabular}{cccccc}
\hline X3-3 & A1 & A2 & A3 & A4 & Weight \\
\hline A1 & 1 & 0.457 & 3.2 & 0.293 & $\mathbf{0 . 1 5 7}$ \\
\hline A2 & & 1 & 5.39 & 0.820 & 0.340 \\
\hline A3 & & & 1 & 0.151 & 0.059 \\
\hline A4 & & & & 1 & $\mathbf{0 . 4 4 4}$
\end{tabular}

Note: $\mathrm{IR}=0.01$ 
Here, the paired judging matrix of each tunnel is analyzed in terms of the ventilation system. As the results show in Table 14, the tunnels are prioritized from first to fifth and Resalat tunnels weighted 0.536, Amir Kabir weighted 0.266 , Niyayesh weighted 0.143 and finally Tohid weighted 0.054 respectively. The standard deviation in the following matrix is 0.02 .

Table 14. The paired judging matrix of each tunnel in terms of the ventilation system

\begin{tabular}{cccccc}
\hline X4 & A1 & A2 & A3 & A4 & Weight \\
\hline A1 & 1 & 2.28 & 7.58 & 4.29 & 0.536 \\
\hline A2 & & 1 & 5.3 & 2.01 & 0.266 \\
\hline A3 & & & 1 & 0.304 & 0.054 \\
\hline A4 & & & & 1 & 0.143 \\
\hline
\end{tabular}

Note: $\mathrm{IR}=0.02$

In this part, the paired judging matrix of each tunnel is analyzed in terms of the possibility of blocking the path and the existence of an alternative path. As the results show in the Table 15, the tunnels are prioritized from first to fifth as Tohid tunnel weighted as 0.534 , Resalat weighted as 0.286 , Niyayesh weighted as 0.110 and finally Amir Kabir weighted as 0.070 respectively. The standard deviation in the following matrix is 0.01 .

In order to determine final weight of each discussed tunnel, Table 16 was used. In the table, indicators were written in horizontal rows with their weights. Then, final gained weights of indexes indicating importance coefficient of each index are multiplied by gained weights for each tunnel and final value for each tunnel is obtained from the total of products.

Finally, as shown in Table 16, the total rate of each urban tunnel has been investigated regarding the se-
Table 15. The paired judging matrix of each tunnel in terms of the possibility of blocking the path and the existence of an alternative path

\begin{tabular}{cccccc}
\hline X5 & A1 & A2 & A3 & A4 & Weight \\
\hline A1 & 1 & 4.02 & 0.465 & 3.07 & $\mathbf{0 . 2 8 6}$ \\
\hline A2 & & 1 & 0.162 & 0.513 & 0.070 \\
\hline A3 & & & 1 & 5.22 & $\mathbf{0 . 5 3 4}$ \\
\hline A4 & & & & 1 & $\mathbf{0 . 1 1 0}$ \\
\hline
\end{tabular}

Note: $\mathrm{IR}=0.01$

lected parameters in which Tohid tunnel is rated as 0.349 , Niyayesh tunnel is rated as 0.279 , Resalat tunnel is rated as 0.197 are the first, second and third priorities respectively in order to change the tunnels' use to the urban safe areas. And finally, Amir Kabir tunnel rated as 0.164 is the last priority. The priority level of each of the tunnels was showed in Fig 6.

As observed, finally, Tohid tunnel was selected as the best tunnel of Tehran in order to be converted into a safe urban space and tunnels of Niyayesh, Resalat and Amir Kabir were placed in the next positions, in order.

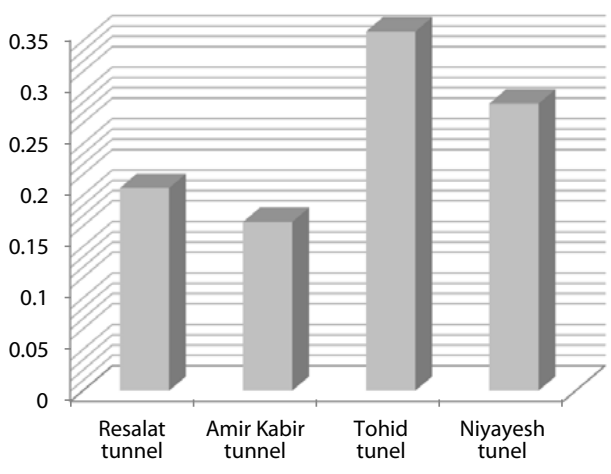

Fig. 6. The priority level of each of the tunnels

Table 16. The final weights of each area

\begin{tabular}{|c|c|c|c|c|c|}
\hline \multicolumn{4}{|c|}{ The obtained opinion of experts } & \multirow{2}{*}{$\begin{array}{l}\text { The coeffi- } \\
\text { cient of } \\
\text { importance }\end{array}$} & \multirow[b]{2}{*}{ Parameter } \\
\hline $\begin{array}{l}\text { Niyayesh } \\
\text { tunnel }\end{array}$ & $\begin{array}{l}\text { Tohid } \\
\text { tunnel }\end{array}$ & $\begin{array}{l}\text { Amir Kabir } \\
\text { tunnel }\end{array}$ & $\begin{array}{l}\text { Resalat } \\
\text { tunnel }\end{array}$ & & \\
\hline 0.226 & 0.483 & 0.215 & 0.076 & 0.402 & Resistance to explosion \\
\hline 0.090 & 0.194 & 0.086 & 0.030 & & Resistance to explosion $\times$ The mean of obtained rate \\
\hline 0.463 & 0.259 & 0.098 & 0.180 & 0.218 & Usable as a safe area and emergency setting \\
\hline 0.100 & 0.056 & 0.021 & 0.039 & & $\begin{array}{c}\text { Usable as a safe area and emergency setting } \times \text { The mean } \\
\text { of obtained rate }\end{array}$ \\
\hline 0.565 & 0.089 & 0.158 & 0.189 & 0.098 & The capability of emergency evacuation \\
\hline 0.055 & 0.008 & 0.015 & 0.018 & & Emergency evacuation $\times$ The mean of obtained rate \\
\hline 0.143 & 0.054 & 0.266 & 0.536 & 0.120 & The ventilation system \\
\hline 0.017 & 0.006 & 0.031 & 0.064 & & The ventilation system $\times$ The mean of obtained rate \\
\hline 0.110 & 0.534 & 0.070 & 0.286 & 0.161 & $\begin{array}{l}\text { The possibility of blocking the path } \\
\text { and the existence of an alternative path }\end{array}$ \\
\hline 0.017 & 0.085 & 0.011 & 0.046 & & $\begin{array}{l}\text { Blocking the path and the existence } \\
\text { of an alternative path } \times \text { The mean of obtained rate }\end{array}$ \\
\hline 0.279 & 0.349 & 0.164 & 0.197 & & The total eight of tunnels \\
\hline
\end{tabular}

Note: $\mathrm{IR}=0.01$ 


\section{Conclusions}

This study tried to investigate Resalat, Niyayesh, Tohid and Amir Kabir tunnels in terms of some parameters such as resistance to explosion, usable as a safe area and emergency setting, the capability of emergency evacuation, the ventilation system and the possibility of blocking the path and the existence of an alternative path.

The obtained data from questionnaires have been rated through which the parameters have been prioritized as follow respectively: first, the resistance for explosion weighted as 0.402 ; second, usable as a safe area and emergency setting rated as 0.218; third, the possibility of blocking the path and the existence of an alternative path for the tunnel rated as 0.161 ; ventilation system rated as 0.120 , and finally the capability of emergency evacuation rated as 0.098 that showed the resistance for explosion is the best criteria in investigating urban-safe space and usable as a safe area and emergency setting rated, the possibility of blocking the path and the existence of an alternative path for the tunnel rated, ventilation system rated, and the capability of emergency evacuation rated take the next places in the ranking, respectively. The tunnels are prioritized using experts' opinion and AHP method. This method is a usable, low cost and precise way of choosing and determining the bests in decisions. This method is a management tool that could be used as an appropriate pattern of managing the use of the best choice among all alternatives. It is obvious that the more precise the information, the more accurate this method will be. So, as the AHP is a precise methodology, with having the general information about alternatives which are obtained through polling the experts, we could choose the best choice.

Finally, the investigated tunnels are prioritized as Tohid weighted as 0.349 , Niyayesh weighted as 0.279 , Resalat weighted as 0.197 and finally Amir Kabir weighted as 0.164 respectively. Regarding the aim of present study as changing the function of Tehran's tunnels to the safe areas and emergency settings at the crisis time, it is necessary to prepare the required arrangements in creating multi-functional areas and to remove their weaknesses in order to be used in crisis times.

\section{References}

Amiri, A. 2011. Psychological considerations of internal architecture designs of public shelters, in Scientific-Investigative Conference of City Planning and Defensive Architecture, 10-11 May, 2011, Tehran, Iran. Technological University of Malek Ashtar.
Badri, M. A. 2001. A combined AHP-GP model for quality control systems, International Journal of Production Economics, 72: 27-40. http://dx.doi.org/10.1016/S0925-5273(00)00077-3

Bambach, M. R. 2010. Unified element and section approach to design of cold-formed steel structures, Journal of Structural Engineering-ASCE 136(4): 343-353.

http://dx.doi.org/10.1061/(ASCE)ST.1943-541X.0000120.

Bitarafan, M.; Hashemkhani Zolfani, S.; Arefi, S. L.; Zavadskas, E. K. 2012. Evaluating the construction methods of coldformed steel structures in reconstructing the areas damaged in natural crises, using the methods AHP and COPRAS-G, Archives of Civil and Mechanical Engineering 12(3): 360-367. http://dx.doi.org/10.1016/j.acme.2012.06.015

Bitarafan, M.; Lale Arefi, S. H.; Hashemkhani Zolfani, S.; Mahmoudzadeh, A. 2013a. Selecting the best design scenario of the smart structure of bridges for probably future earthquakes, in The 11th International Scientific conference on Modern Building Materials Structures and Techniques, MBMST, 16-17 May 2013, Vilnius, Lithuania. Procedia Engineering 57: 193-199.

http://dx.doi.org/10.1016/j.proeng.2013.04.027

Bitarafan, M.; Hosseini, S. B.; Abazarlou, S.; Mahmoudzadeh, A. 2013b. Selecting the optimal composition of architectural forms from the perspective of civil defense using AHP and IHWP methods, Architectural Engineering and Design Management 11 (2): 137-148.

http://dx.doi.org/10.1080/17452007.2013.802982

Bobylev, N. 2010. Underground space in the Alexanderplatz Area, Berlin: research into the quantification of urban underground space use, Tunnelling and Underground Space Technology 25 (5): 495-507.

http://dx.doi.org/10.1016/j.tust.2010.02.013

Cano-Hurtado, J. J.; Canto-Perello, J. 1999. Sustainable development of urban underground space for utilities, Tunnelling and Underground Space Technology 14 (3): 335-340. http://dx.doi.org/10.1016/S0886-7798(99)00048-6

Da gdeviren, M. 2008. Decision making in equipment selection: an integrated approach with AHP and PROMETHEE, Journal of Intelligent Manufacturing 19: 397-406. http://dx.doi.org/10.1007/s10845-008-0091-7

Durmisevic, S. 1999. The future of the underground space, Cities 16(4): 233-245. http://dx.doi.org/10.1016/s0264-2751(99)00022-0

Fars News Agency [online], [cited 9 April 2015]. Available from Internet: http://www.farhangnews.ir/content/74741.

FEMA 453. 2006. Design Guidance for Shelters and Safe Rooms. US Department of Homeland Security.

Fesharaki, J; Gharbaghi, S, J. 2011. The book of principles of design and construction haven safe. Nokhbe Sazan Publication.

Fouladgar, M. M.; Yazdani-Chamzini, A.; Zavadskas, E. K. 2011. An integrated model for prioritizing strategies of the Iranian mining sector, Technological and Economic Development of Economy 17(3): 459-484. http://dx.doi.org/10.3846/20294913.2011.603173.

Gudienè, N.; Banaitis, A.; Podvezko, V.; Banaitienė, N. 2014. Identification and evaluation of the critical success factors for construction projects in Lithuania: AHP approach, Journal of Civil Engineering and Management 20(3): 350359. http://dx.doi.org/10.3846/13923730.2014.914082

Hamshahrionline [online], [cited 9 April 2015]. Available from Internet: http://hamshahrionline.ir/details/241204. 
Hashemkhani Zolfani, S.; Esfahani, M. H.; Bitarafan, M.; Zavadskas, E. K.; Lale Arefi, Sh. 2013. Developing a new hybrid MCDM method for selection of the optimal alternative of mechanical longitudinal ventilation of tunnel pollutants during automobile accidents, Transport 28(1): 89-96. http://dx.doi.org/10.3846/16484142.2013.782567

He, L.; Song, Y.; Dai, S.; Durbak, K. 2012. Quantitative research on the capacity of urban underground space - the case of Shanghai, China, Tunnelling and Underground Space Technology 32: 168-179.

http://dx.doi.org/10.1016/j.tust.2012.06.008

Hoeven, F.; Nes, A. 2014. Improving the design of urban underground space in metro stations using the space syntax methodology, Tunnelling and Underground Space Technology 40: 64-74. http://dx.doi.org/10.1016/j.tust.2013.09.007

Hruška, R.; Průšaa, P.; Babića, D. 2014. The use of AHP method for selection of supplier, Transport 29(2): 195-203. http://dx.doi.org/10.3846/16484142.2014.930928

Işıklar, G.; Büyüközkan, G. 2007. Using a multi-criteria decision making approach to evaluate mobile phone alternatives, Computer Standards \& Interfaces 29: 265-274. http://dx.doi.org/10.1016/j.csi.2006.05.002

Kashi, A. A. 2009. Assessment of passive defense in tunnels of people's settlement: Master's Thesis. Technological University of Malek Ashtar.

Kenward, J. K. 2002. Design recommendations for multi-storey and underground car parks. $3^{\text {rd }} \mathrm{ed}$. The Institution of Structural Engineers.

Khandan, M. 2010. Ergonomic studies of safe space design from prespective of civil defense. Malek Ashtar university of Technology.

Lale Arefi, SH.; Bitarafan, M. 2013. Assessment of various methods of rehabilitation in underground structures against threats caused by explosion through AHP (Analytic Hierarchy Process) method, Tunneling and Underground Spaces Engineering 2(1): 65-74 (in Persian).

Nosal, K; Solecka, K. 2014. Application of AHP method for multi-criteria evaluation of variants of the integration of urban public transport, Transportation Research Procedia 3: 269-278. http://dx.doi.org/10.1016/j.trpro.2014.10.006

Saaty, L. T. 1980. The analytic hierarchy process. New York: McGraw Hill Company.

Sivilevicius, H. 2011a. Modeling the Interaction of Transport System Elements, Transport 26(1): 20-34. http://dx.doi.org/10.3846/16484142.2011.560366

Sivilevicius, H. 2011b. Application of expert evaluation method to determine the importance of operating asphalt mixing plant quality criteria and rank correlation, Baltic Journal of Road and Bridge Engineering 6(1): 48-58.

http://dx.doi.org/10.3846/bjrbe.2011.07

Sterling, R.; Admiraal, H.; Bobylev, N.; Parker, H.; Godard, J.; Vähäaho, I.; D. F. Rogers, C.; Shi, X.; Hanamura, T. 2012. Sustainability issues for underground space in urban areas. Proceedings of the ICE - Urban Design and Planning 165(4): 241-254. http://dx.doi.org/10.1680/udap.10.00020

US Department of Homeland Security 2006. P-320. Taking Shelter from the Storm: Building a Safe Room for Your Home or Small Business.

Vafamehr, M. 2011. Passive defense in designing and implementation of safe structures for shelters, scientific-investigative, in Conference of City Planning and Defensive Architecture, 10-11 May 2011, Tehran, Iran. Technological university of Malek Ashtar.
Wang, J. J.; Yang, D. L. 2007. Using a hybrid multi-criteria decision aid method for information systems outsourcing, Computers and Operation Research 34: 3691-3700. http://dx.doi.org/10.1016/j.cor.2006.01.017

Zahedifar, S. 2010. Principles of architectural design for safety and supply of vital underground safe spaces. Tehran: Technological University of Malek Ashtar.

\section{JALAL NAKHAEI}

Department of Art and Architecture Engineering in Islamic Azad University, Central Tehran Branch, Iran.

E-mail: jalal.nakhei@gmail.com

Research interests: Architecture engineering, crisis management, safe spaces and structures

\section{MAHDI BITARAFAN}

Department of Civil Engineering in Research Institute of Shakhes Pajouh, Isfahan, Iran. E-mail: mb_civil90@yahoo.com

Research interests: Civil engineering, earthquake engineering, multiple criteria decision making, explosion protection.

\section{SHAHIN LALE AREFI}

Department of Civil Engineering in University of Mohaghegh Ardabili, Ardabil, Iran.E-mail: shahin.arefi@gmail.com

Research interests: Civil engineering, earthquake engineering, damage detection, experimental, composite materials, retrofitting and strengthening on steel and concrete structures, multiple criteria decision making. 